\title{
Problems of protecting the rights of taxpayers in the framework of examining the materials of a tax audit and making a decision by a tax authority
}

\author{
Maxim Igorevich Zimulkin* \\ Ural State Law University, Yekaterinburg, Russia
}

\begin{abstract}
The subject of the study is the Russian Federation legislation, case law, as well as domestic and foreign doctrine, which allow us to establish the main problems of determining the concept of procedural norms' materiality of breach when examining the materials of a tax audit and making a decision by a tax authority. The object of the study is public relations on the examination of the materials of the tax audit and the decision of the tax authority on the audit results. The author examines in detail the legal aspects related to the procedural issues of notifying the taxpayer related to the place and time of tax authority's examination of the audit materials, compliance of the decision with the procedural requirements of the law, compliance with the deadlines for examination of the tax audit materials and making a decision on them, as well as additional tax control measures. The author pays special attention to the problems of qualification of procedural violations as significant ones, entailing the cancellation of the decision of the tax authority. The author formulates the criterion of procedural norms' materiality of breach of the Russian Federation legislation on taxes and fees when considering the materials of a tax audit and making a decision by the tax authority.
\end{abstract}

\section{Introduction}

The modern Russian legal doctrine is based upon the indisputable relevance of procedural norms of the legislation of the Russian Federation on taxes and fees. These norms are significant when examining the tax audit materials and deciding by the tax authority [1].

Pursuant to paragraph 2 of Article 101 of the Tax Code of the Russian Federation, consideration of tax audit materials takes place with the participation of taxpayer representatives, who must be previously and properly notified of the time and place of consideration of tax audit materials [2]. Violation of the taxpayer's right to participate in examining the audit materials and the provision of explanations is a significant violation of procedural rules of tax legislation (paragraph 14 of Article 101 of the Tax Code of the Russian Federation) [2].

It should be noted that this rule is consistent with the "the taxpayer's right to be heard by the tax administration" principle [3], which is recognized by modern legal doctrine as one of the most significant procedural principles of tax law [4]. The right to be heard is considered in international practice to be the minimum standard of procedural guarantees of a taxpayer since it is inextricably linked with the right to judicial protection [5].

In particular, the European Court of Human Rights practice regarding inappropriate notification by courts of persons involved in a case should be taken into consideration. The case law of the European Court of Human Rights is of the view that the specified action (inaction) is a violation of Article 6 of the Convention for the Protection of Human Rights [6], which is an expression of the concept of "due process of law" (due process of law) [7].

It should be assumed that a similar approach should also be applied to the legal relationship between the taxpayer and the tax authority at the stage of consideration of the tax audit materials by the tax authority.

According to the prevailing opinion in the tax law doctrine, the right of a taxpayer to be heard includes the right for the taxpayer to present own position and the obligation of the tax authority to take this position into account, giving it an assessment in the reasoning part of the decision [8].

As noted by F. Baker and P. Pistone, at present, the overwhelming majority of states guarantee the taxpayer the right to express their position before the tax authority makes a decision [5].

Of particular interest, in this case, is the ambiguous approach of the courts of the Italian Republic to the exercise of the taxpayer's right to be heard [9].

According to the law enforcement approach formed in the Italian Republic, the violation of the taxpayer's right to provide a position before the decision of the tax authority is a significant procedural violation when it

Corresponding author:mi.zimulkin@gmail.com 
comes to taxes, the legal regulation of which is harmonized with the legislation of the European Union (for example, VAT). In tax procedures related to the calculation and payment of other taxes (for example, profit tax), the courts may not recognize the violation of the taxpayer's right to be heard as an unconditional basis for canceling the tax authority's decision [10].

In the Netherlands, "the right to be heard" is not formally enshrined in tax legislation [11]. However, it is an unwritten rule when examining tax disputes by courts and may be the basis for recognizing the tax authority's decision as illegal [6]. In Germany, Switzerland, and Poland, the "right to be heard" directly follows these states' Basic Law [10].

As noted in legal science [10], in the Kingdom of Sweden, the "right to be heard" is an integral part of the right to a fair trial [12]. It is also believed [10] that in the French Republic, "the right to be heard" is an integral element of the adversarial principle [13].

The procedure for examining the audit materials and making a decision is regulated in the tax legislation of the Russian Federation in the most detail. This circumstance can be explained by the special significance of the taxpayer's procedural actions under consideration. When examining the tax audit materials, the taxpayers, who have already been familiar with all the materials in detail, can fully express their position. It should be noted that the procedure under consideration is a rather important stage for the tax authorities. Based on the collected materials, it is within the framework of this procedure that legally significant circumstances are established. The final law enforcement action is issued. Under the significance presented, the vast majority of tax disputes related to the application of procedural norms arise from the disagreements between taxpayers and tax authorities at the stage of examining the materials of the audit and making a decision.

As the most common categories of disputes related to the consideration of tax audit materials and making a decision on them, one can single out disputes based on following principles:

(1) failure to notify or improper notification of the taxpayer about the place and time of consideration of the audit materials;

(2) inconsistency of the decision content based on the results of consideration of the inspection materials with the requirements of the current legislation;

(3) exceeding the time limits for consideration of tax audit materials and making a decision on them;

(4) violation of the procedure for carrying out additional tax control measures.

Based on the above, it is considered necessary to consider the main problems of defining the concept of materiality of breach of procedural norms when examining the materials of a tax audit and making a decision by the tax authority.

\section{Materials and methods}

Several generals and specific scientific methods are used during the research, particularly dialectics, analysis, synthesis, generalization, abstraction, and induction. The ranking method is used in the study of judicial practice. The work is largely based on the inductive method of theoretical research. The used private scientific methods include formal legal, historical legal, and comparative legal.

\section{Results}

The procedure for examining materials of a tax audit and making a decision is provided in Article 101 of the Tax Code of the Russian Federation [2].

Certain aspects of the application of Article 101 of the Tax Code of the Russian Federation are explained by various acts of interpretation.

In particular, paragraphs 37 - 45 of the Decision of the Plenum of the Supreme Commercial Court of the Russian Federation dated July 30, 2013 No. 57 contain clarifications on specific issues related to the consideration of tax audit materials [14].

For the research being conducted, the provisions of paragraph 14 of Article 101 of the Tax Code of the Russian Federation are of most significant interest, containing the main rule guaranteeing compliance with the procedure for examining the materials of the audit and making a decision.

The indicated provisions provide that a significant violation of the procedural norms of the legislation of the Russian Federation on taxes and fees when examining the materials of the audit may be an unconditional basis for the cancellation of a non-normative legal act of the tax authority.

These provisions of the Russian Federation's legislation on taxes and fees establish the need for strict compliance with procedural tax and legal norms.

Even though these regulations are formally aimed at regulating relations on the consideration of inspection materials and making a decision, in reality, as the court practice shows, the indicated rules are also applied in the regulation of other tax control measures.

It should also be noted that the list of violations of procedural norms, which entail the abolition of nonnormative legal acts, specified in paragraph 14 of Article 101 of the Tax Code of the Russian Federation, is not exhaustive, which, in fact, indicates the need to determine the criterion of the materiality of breach of procedural norms in the application of tax legislation.

It is worth drawing attention the explanations contained in paragraph 40 of the Decision of the Plenum of the Supreme Commercial Court of the Russian Federation dated July 30, 2013 No. 57. This provision indicates that failure to notify or inappropriate notification of the inspected person about the time and place of consideration of the inspection materials should be recognized as a significant violation of procedural norms entailing the cancellation of the tax authority's decision [14].

A similar position is confirmed by well-established judicial practice [15].

Thus, it can be concluded that law enforcement practice recognizes failure to notify or inappropriate 
notification of the taxpayer about the time and place of examination of the inspection materials as a significant violation of procedural rules of tax legislation, entailing the cancellation of the decision the tax authority.

However, issues of non-notification or inappropriate notification represent a deeper category than one might initially assume.

Judicial practice shows the presence of many tax disputes in which the court needs to find out which notification can be recognized as appropriate and which is not considered as such and will be recognized as a significant violation of procedural rules.

In particular, it is possible to single out situations when the taxpayer received the notification only on the day of consideration of the tax audit materials, or the said notification was delivered to a person who does not have the necessary powers.

The courts were investigating the issue of consideration by the tax authority of the audit materials when the taxpayer received a notification after examining the materials of the audit or on the day of the said consideration. At the same time, the courts proceed from the fact that such notification cannot be recognized as appropriate, and the decision made based on the results of the consideration should be canceled due to a significant violation of procedural rules of tax legislation [16].

In some cases, a significant violation of the procedure entailing the cancellation of the tax authority's decision may be the delivery of a notice of the time and place of consideration of the tax audit materials to a person who does not have the authority.

Notably, in the Decision of the Commercial Court of the Central District dated 03.02.2015 No. F10-4996 / 2014 in case No. A54-2952 / 2013,the court indicated that the tax authority at the time of sending the notification, as well as at the time of consideration of the audit materials, knew that the person who had previously acted by power of attorney on behalf of the taxpayer did not have the necessary powers.

In the context of the above, the consideration of the tax audit materials, in the event that only the specified person was notified, was recognized as a significant violation of procedural rules of tax legislation [17].

It should also be noted that in judicial practice, there are precedents for invalidating the tax authority's decision in cases when subsequently, including based on the results of the forensic examination, the power of attorney of the representative who received the notification was recognized as falsified [18].

There is a rare but indicative example of recognizing a tax authority's decision as illegal in the event of improper notification of a debtor in bankruptcy proceedings.

In the framework of the case, which ended in the issuance of the Decision of the Commercial Court of the North-Western District of January 22, 2016, in case No A42-596 / 2015, the circumstances were considered in which the tax authority sent a bankrupt taxpayer by registered mail a notice of the time and place of consideration of the audit materials. This notice was sent to the address of the bankrupt taxpayer indicated in the Unified State Register of Legal Entities [19].

However, since the taxpayer was in the bankruptcy proceedings, the authorized representative of the debtor under the provisions of Articles 126, 129 of the Federal Law of 26.10.2002 No. 127-FZ "On insolvency (bankruptcy)" [20] was the bankruptcy commissioner who was not located at the location of the taxpayerbankruptcy. The tax authority knew these circumstances.

Because the bankruptcy commissioner was not located at the location of the bankrupt taxpayer, he did not have the opportunity to receive the sent notification and, accordingly, to participate in the examination of the inspection materials and submit objections on time.

Having examined the above, the court determined that in this case, the tax authority did not correctly notify the authorized representative of the taxpayer, which is a significant violation of procedural rules, entailing the cancellation of the tax authority's decision.

The analysis of the presented judicial practice allows concluding that the mere failure to notify or inappropriate notification of the person in respect of whom the audit is being carried out is recognized as a significant violation of procedural norms when applying the legislation of the Russian Federation on taxes and fees. Accordingly, this decision is an unconditional basis for canceling the decision of the tax authority. However, the study of individual precedents related to the assessment of the actions (inaction) of the tax authorities upon the notification of the taxpayer about the examination of the audit materials allows drawing the following conclusion. The specific circumstances of tax disputes have significant differences, which indicates the multifaceted nature of the problem under study and the need for detailed consideration by the court of all the circumstances of a potential violation.

Recognition of a procedural violation, the absence of the necessary calculations in the tax authority's decision is the most interesting from the point of view of determining the criterion of the materiality of breach of procedural norms in the application of tax legislation.

Commercial Court of the Volga District analyzed this category of procedural violations of examining tax audit materials and making a decision. It is considered appropriate to consider the Decision of the Commercial Court of the Volga District dated 03.02.2015 No. F0636931 / 2018 in case No. A12-33423 / 2017 [21].

Within the framework of this case, the tax authority decided to bring the taxpayer to tax liability, establishing profit tax arrears.

At the same time, the substantive part of the tax authority's decision did not allow checking the established arrears since the law enforcement action did not contain the corresponding calculations.

The judicial act also states that the tax authority did not provide a single document related to the tax period being audited in transactions with disputable counterparties, referring to the tax audit report. There is also no information about the primary documents and the amounts of excluded expenses.

In the opinion of the court, the lack of this information and calculations of the tax payable does not 
allow reliably establishing the number of expenses excluded by the tax authority from the calculation of income tax.

Based on the above, the court concludes that the absence of the necessary calculations in the decision is a significant violation of the procedure for examining the audit materials and making a decision on bringing to responsibility for committing a tax violation.

The above conclusions of the court can be recognized as reasonable and consistent with the current legislation of the Russian Federation on taxes and fees. The reason is paragraph 8 of Article 101 of the Tax Code of the Russian Federation. The tax authority's decision must be complete in describing the actual circumstances and the legal qualification of the committed act [2].

Inconsistency of the decision of the tax authority with the specified norm may lead to the impossibility of verifying the legality and validity of the decision of the territorial tax authority by a higher tax authority or court.

In addition, in the absence of the tax authority's decision to calculate the tax payable, the taxpayer is deprived of the opportunity to submit justified objections and counter-calculation.

Twelfth Commercial Court considered the precedents related to the qualification of the substantive incompleteness of the tax authority's decision as procedural violations. It is also appropriate to consider the court's conclusions, reflected in the Decision of the Twelfth Commercial Court of Appeal of 25.04.2018 in case No. court of the Volga District of August 22, 2018, No. F06-36242 / 2018 in case No. A06-7063 / 2017) [22].

The circumstances of the designated case indicate that the taxpayer could not submit all the requested documents to the tax authority since the investigating authorities attached them to the criminal case materials.

At the same time, the tax authority, without resorting to calculating the tax payable using the calculation method, calculated the tax based on the available documents.

These actions of the tax authority led to a decision to hold the taxpayer liable for committing a tax offense, the conclusions of which, including the calculation of arrears, were not supported by any appropriate evidence.

Based on the above, the court concluded that from the decision of the inspection it is impossible to establish which specific facts were qualified as tax offenses, with reference to documents and other information confirming these circumstances, to verify the correctness of additional tax assessment, as well as penalties and fines for the contested violation.

In this part, the tax authority violated the provisions of subparagraph 12 of paragraph 3 of Article 100, paragraph 8 of Article 101 of the Code, which is an independent basis for recognizing the contested decision of the tax authority as invalid [22].

Thus, the court pointed out flaws in the decision of the tax authority. These shortcomings are expressed in the impossibility of verifying the validity of bringing to tax liability and analyzing the calculation of arrears. They should be recognized as a significant violation of procedural tax and legal norms, which is an independent basis for the tax authority's decision.

A similar conclusion is also contained in the Thirteenth Commercial Court of Appeal Decision dated December 27, 2017, No. 13AP-17062/2017 in case No. A56-64382 / 2016. This Decision indicates that "when analyzing the information displayed in the Table, and when examining the case materials, it is not possible to establish the grounds for controversial additional charges concerning specific financial and economic relations of the entrepreneur and counterparties, the validity of these amounts in law and size is not possible" [23].

According to the court, the above circumstances indicate a significant violation by the tax authority of the procedure for examining the audit materials and the issuance of a subsequent non-normative legal act.

It should be noted that the approach formed in the current judicial practice generally corresponds to the position outlined in paragraph 10 of the Information Letter of the Presidium of the Supreme Commercial Court of the Russian Federation dated March 17, 2003 No. 71 of the Supreme Commercial Court of the Russian Federation. This Information Letter establishes that the court must refuse to satisfy the tax authority's claim on the collection of a fine from the taxpayer if the nature and circumstances of the committed tax offense are not indicated in the decision to hold the taxpayer liable [24].

The explanations under consideration were widespread in the practice of arbitration courts before the entry into force of the novellas that modified the structure and content of Article 101 of the Tax Code of the Russian Federation [25].

It should be concluded that judicial practice over a long period, regardless of any legislative novelties, determines the shortcomings of the tax authority's decision. These decisions do not allow objectively correlating the information contained in the tax audit materials with the conclusions of the tax authority's decision, as a significant violation of procedural rules of tax legislation.

We investigated the categories of violations of procedural norms of the legislation of the Russian Federation on taxes and fees. It is also necessary to analyze the problems associated with exceeding the permissible time limits for examining audit materials and making a decision by the head (deputy's head) of the tax authority.

A designated official is based on the results of the examination of the audit materials. According to the provisions of paragraph 1 of Article 101 of the Tax Code of the Russian Federation, the materials of the tax audit and the taxpayer's objections must be considered by the leadership of the territorial tax authority. So, the designated official is obliged to decide within a period not exceeding ten days from the date of the expiration of the term for the submission of by the taxpayer objections. The specified period can be increased, but not more than one month [2].

Based on the results of consideration of the audit materials, additional tax control measures were carried out. Then the tax authority's decision shall be made no later than ten days from the date of expiration of the 
period for the taxpayer to submit objections to amendments to the tax audit act.

The legislator has set clear terms for examining tax audit materials and making a decision on the relevant materials. According to this definition, it is necessary to investigate the approach of the law enforcement officer in matters of qualification of violations by the tax authority of the designated deadlines from the point of view of recognizing such a violation as an unconditional basis for decisions of the tax authority.

Before analyzing the relevant judicial practice, it should be noted that the tax authority itself does not consider the violation of the terms for examining the materials of the audit and making a decision on them a violation, entailing the unconditional cancellation of a non-normative legal act.

In particular, the indicated position is stated in the letters of the Federal Tax Service of the Russian Federation [26].

The analysis of judicial practice results also indicates that the courts recognize the violation of the terms for examining the tax audit materials and making the decision as a significant violation of procedural rules of tax legislation, entailing some legal consequences.

To study the possibility of recognizing the excess of the time limit for examining the inspection materials and making a decision on them as a significant procedural violation, the case of Element-Trade LLC (A60-22795 / 2019) [27] is of interest.

The circumstances of this case make it possible to establish that a repeated field tax audit was carried out concerning the taxpayer, which resulted in the act of 12/20/2017.

Considering the above, in January 2018, a decision should have been made based on the results of consideration of the tax audit materials.

By the decision of January 30, 2018, it was indicated that additional tax control measures were required by February 28, 2020.

In order to establish the circumstances that are important for obtaining information about the relationship of the taxpayer with counterparties, the tax authority sent a request to the competent authorities of the Swiss Confederation.

From that moment, examination of the tax audit materials and the issuance of the corresponding decision were postponed at least five times. The time limit in which the decision should be made was exceeded by more than one year.

In connection with the above, the taxpayer applied to the court with a demand aimed at invalidating the decisions of the tax authority to extend the time of the on-site tax audit.

As the consequences of the violations committed by the tax authority, the taxpayer indicated the banks' refusal to lend to the taxpayer regarding whom the tax audit is being carried out.

However, the courts of the first appeal and cassation instance refused to satisfy the taxpayer's claims.

In the context of the above, there are notable conclusions of the court set out in the Decision of the
Commercial Court of the Ural District dated 04.02.2020

No. F09-9501 / 19 in case No. A60-22795 / 2019.

The court assessed that the tax authority exceeded the time limits for consideration of tax audit materials and decision-making as provided for by law. The cassation court concluded that the failure to comply with the terms of consideration of the tax audit materials or additional control measures was not attributed to significant violations of procedural provisions of tax legislation [27].

It should be assumed that the established law enforcement approach is due to the clarifications contained in paragraph 31 of the Decisions of the Plenum of the Supreme Commercial Court dated July 30, 2013 No. 57 [14].

Based on the above, it should be concluded that at the moment in judicial practice, a law enforcement approach has been formed, according to which the violation by officials of the tax authorities of the terms provided for in paragraph 1 of Article 101 of the Tax Code of the Russian Federation is a significant violation of the procedural rules of the legislation of the Russian Federation on taxes and fees

At the same time, violation by officials of the tax authorities of the terms for examining the audit materials does not imply the cancellation of the tax authority's decision. However, it entails a different legal consequence - the inability to extend the deadlines for implementing measures for the enforcement of taxes and fees.

Considering the problems applying procedural norms of tax legislation when examining the audit materials and making a decision, it is considered expedient to consider the procedural aspects associated with additional tax control measures.

Paragraph 6 of Article 101 of the Tax Code of the Russian Federation, the legislation of the Russian Federation on taxes and fees, establishes the right of officials, if there is a need for additional evidence, to carry out additional control measures (paragraph 6 of Article 101 of the Tax Code of the Russian Federation) [2].

Additional tax control measures may be carried out following the consideration of the tax audit materials and before deciding on the results of the tax audit. As a general rule, the duration of additional events should not exceed one month.

When deciding on the appointment of additional measures of control measures, the tax authority is obliged to establish the grounds for carrying out these measures, the time frame, and form [2].

Currently, there are many tax disputes in which taxpayers refer to the tax authority's violation of the procedure for carrying out additional tax control measures.

The most common problem in this category is the actual transformation of additional tax control measures into an independent tax audit. That is the commission by tax officials of attempts to establish new tax offenses committed by the taxpayer within the framework of additional measures instead of a deeper check of previously established circumstances. 
The inadmissibility of this approach was separately noted in paragraph 39 of the Decision of the Plenum of the Supreme Commercial Court dated July 30, 2013 No. 57 [14].

It should be noted that the Constitutional Court of the Russian Federation also pointed out that the purpose of additional tax control measures is precisely to clarify certain circumstances associated with the detected offense [28].

The Federal Tax Service of the Russian Federation agrees with this interpretation of the provisions of paragraph 6 of Article 101 of the Tax Code of the Russian Federation. The Federal Tax Service of the Russian Federation concluded that violations previously unrecorded in the inspection report could not be entered after additional tax control measures [29].

Thus, additional tax control measures cannot identify new tax offenses committed by the person in respect of whom the tax audit was carried out.

For the most part, tax disputes related to the issues of carrying out additional tax control measures are based on the problems of determining the essence of the results of additional measures - new information should deepen, and not expand, the content of the results of a tax audit. In this case, the court establishes the extent to which the content of the decision corresponds to the conclusions of the tax audit act [30].

Thus, it can be concluded that bringing the taxpayer to a tax liability for offenses revealed at the stage of additional tax control measures is unacceptable. This conclusion is confirmed by the positions of the Supreme Commercial Court of the Russian Federation and the Constitutional Court of the Russian Federation. The fiscal authority also recognizes it. The tax authority has the right to make a decision that includes conclusions about the committed tax offense if the tax audit act contains at least some indication of the actions committed by the taxpayer. In this case, the evidence of these actions is confirmed by evidence obtained as part of additional tax control measures.

\section{Conclusion}

The study is based on an analysis of the provisions of the legislation of the Russian Federation on taxes and fees, the positions of the Constitutional Court of the Russian Federation, the Supreme Court of the Russian Federation, and the Supreme Commercial Court of the Russian Federation, as well as relevant judicial practice. This analysis indicates that a precise law enforcement approach has developed in matters of reviewing the materials of the audit and making a decision on them, which makes it possible to clearly define the criterion of the materiality of breach of procedural norms in the application of tax legislation.

In tax disputes related to the examination of the audit materials and the adoption of a decision, significant violations of procedural norms can be recognized: failure to notify or inappropriate notification of the taxpayer about the examination of the audit materials; shortcomings in the content of the decision of the tax authority (for example, incompleteness of the circumstances of the alleged tax offense, lack of calculations of arrears and penalties); violation of the terms of consideration of tax audit materials. The legal consequence of the indicated violation is not the unconditional cancellation of the tax authority's decision, but the impossibility of replenishing the temporary resource for the implementation of measures for the enforcement of taxes and fees; violation of the procedure for carrying out additional tax control measures.

Acknowledgments: The reported study was funded by RFBR, project number 20-311-90046.

\section{References}

1. D.V. Vinnitskiy, Tax procedural law and tax process: problems of formation, Legislation, 2, 2331 (2003)

2. Tax Code of the Russian Federation (part one) dated July 31, 1998 No. 146-FZ (with subsequent amendments and additions on July 20, 2020). Retrieved from: ConsultantPlus.

3. A. Eijsden, B. Killmann, F. Meussen, J. Dam, D. Smit, General Part, in Procedural Rules in Tax Law in the Context of European Union and Domestic Law (M. Lang, P. Pistone, J. Schuch, C. Staringer (eds.) (Kluwer Law International, 2010) pp. 3-48.

4. P. Pistone, General Report, in Tax Procedures (P. Pistone, ed.) EATLP Annual Congress (Madrid 2019) p. 26.

5. P. Baker, P. Pistone, General Report, in Cahiers de droit fiscal international: IFA Basel congress 2015, volume 100 B. The practical protection of taxpayers' fundamental rights (P. Baker, P. Pistone, eds.) (Verlag Den Haag: Sdu Uitgevers, Den Haag, 2015) p. 43.

6. Convention for the Protection of Human Rights and Fundamental Freedoms (Concluded in Rome on 04.11.1950) (as amended on 13.05.2004) (together with Protocol [No. 1] (Signed in Paris on 20.03.1952), Protocol No. 4 on ensuring certain rights and freedoms in addition to those already included in the Convention and the first Protocol thereto (Signed in Strasbourg 09.16.1963), Protocol No. 7 (Signed in Strasbourg 11.22.1984)). Retrieved from: Consultant Plus.

7. Decision of the European Court of Human Rights of 06/28/2018 in the case of Grigorieva and others v. The Russian Federation (complaint No. 57477/14, 77878/14, 9236/15, 4197/16, 13476/16). Retrieved from: http://www.echr.coe.int (Date of access 05/28/2021).

8. J. Cocott, P. Pistone, R. Miller, Public International Law and Tax Law (USLU and the BRICS Law Institute, Yekaterinburg, 2021) $114 \mathrm{p}$.

9. A. Carinci, Italy, in Tax Procedures (P. Pistone, ed.) EATLP Annual Congress (Madrid 2019) pp. 645672. 
10. N. Cicin-Sain, Joint and Simultaneous Audits, in Tax Procedures (P. Pistone, ed.) EATLP Annual Congress (Madrid 2019) pp. 151-176.

11. D. Hout, Netherlands, in Tax Procedures (P. Pistone, ed.) EATLP Annual Congress (Madrid 2019) pp. 707-746.

12. A.M. Hambre, Sweden, in Tax Procedures (P. Pistone, ed.) EATLP Annual Congress (Madrid 2019) pp. 933-972.

13. G. Cavalier, France, in Tax Procedures (P. Pistone, ed.) EATLP Annual Congress (Madrid 2019) pp. 467-510.

14. Decision of the Plenum of the Supreme Commercial Court of the Russian Federation dated July 30, 2013 No. 57 "On some issues arising from the application by arbitration courts of part one of the Tax Code of the Russian Federation". Retrieved from: ConsultantPlus.

15. Decision of the Presidium of the Supreme Commercial Court of the Russian Federation dated January 13, 2011 No. 10519/10 on case No. A4124669 / 09. Retrieved from: ConsultantPlus.

16. Decision of the Commercial Court of the Volga Region dated February 28, 2018 No. F06-29834 / 2018 in case No. A12-13646 (2017). Retrieved from: ConsultantPlus.

17. Decision of the Commercial Court of the Central District of 03.02.2015 No. F10-4996 / 2014 in case No. A54-2952 (2013). Retrieved from: ConsultantPlus.

18. Decision of the Commercial Court of the East Siberian District dated March 29, 2018 No. F02-45 / 2018 in case No. A33-22682 (2016). Retrieved from: ConsultantPlus.

19. Decision of the Commercial Court of the NorthWest District of January 22, 2016 in case No. A42596 (2015). Retrieved from: ConsultantPlus.

20. Federal Law On Insolvency (Bankruptcy) dated 26.10.2002 No. 127-FZ (with subsequent amendments and additions as of 01.09.2020). Retrieved from: ConsultantPlus.

21. Decision of the Commercial Court of the Volga Region dated 03.02.2015 No. F06-36931 / 2018 in case No. A12-33423 (2017). Retrieved from: ConsultantPlus.
22. Decision of the Twelfth Commercial Court of Appeal dated 25.04.2018 in case No. A06-7063 (2017). Retrieved from: ConsultantPlus.

23. Decision of the Thirteenth Commercial Court of Appeal dated December 27, 2017 No. 13AP$17062 / 2017$ in case No. A56-64382 (2016). Retrieved from: ConsultantPlus.

24. Information letter of the Presidium of the Supreme Commercial Court of the Russian Federation dated 17.03.2003 No. 71 "Review of the practice of resolving cases by arbitration courts related to the application of certain provisions of part one of the Tax Code of the Russian Federation". Retrieved from: "ConsultantPlus".

25. Federal Law of 27.07.2006 No. 137-FZ "On Amendments to Part One and Part Two of the Tax Code of the Russian Federation and to Certain Legislative Acts of the Russian Federation in Connection with the Implementation of Measures to Improve Tax Administration". Retrieved from: ConsultantPlus.

26. Letter of the Federal Tax Service of Russia dated 10.01.2019 No. ED-4-2 / 55 "On compliance with the procedural deadlines provided for by the Tax Code of the Russian Federation". Retrieved from: ConsultantPlus.

27. Decision of the Commercial Court of the Ural District of 02/04/2020 No. F09-9501 / 19 in case No. A60-22795 (2019). Retrieved from: ConsultantPlus.

28. Decision of the Constitutional Court of the Russian Federation of 14.07.2005 No. 9-P "In the case of checking the constitutionality of the provisions of Article 113 of the Tax Code of the Russian Federation in connection with the complaint of citizen G.A. Polyakova and the request of the Federal Commercial Court of the Moscow District". Retrieved from: ConsultantPlus.

29. Letter of the Federal Tax Service of Russia dated 19.10.2018 No. ED-4-2 / 20515 @. Retrieved from: SPS ConsultantPlus.

30. Determination of the Supreme Court of the Russian Federation dated 20.01.2020 No. 308-KG18-24069 in case No. A53-36852 (2017). Retrieved from: ConsultantPlus. 